\title{
Educating pastoralists and extension officers on diverse livestock diseases in a changing environment in Tanzania
}

\author{
Christopher R Gustafson ${ }^{1,2^{*}{ }^{+}}$, Elizabeth VanWormer ${ }^{1+}$, Rudovick Kazwala ${ }^{3}$, Asha Makweta ${ }^{3}$, Goodluck Paul ${ }^{3}$, \\ Woutrina Smith ${ }^{1}$ and Jonna AK Mazet ${ }^{1}$
}

\begin{abstract}
East African pastoralists and their livestock are vulnerable to alterations in resource availability and disease transmission and frequently face poor access to livestock health services. Government veterinarians tasked with guiding health services must prioritize livestock health risks and allocate limited resources across disparate ecosystems with different disease threats. To identify livestock diseases of concern and strategies for improving herd health and resilience, we conducted community focus groups with pastoralists and interviewed pastoralist household leaders, village extension officers, and government veterinary officials in south-central Tanzania, an area experiencing rapid population growth and environmental change. All participants discussed pastoralist access to livestock health services, livestock disease priorities, and means to improve livestock health.

Perceptions of diseases of importance differed among pastoralists, extension officers, and government veterinarians. Spatial differences in diseases of concern among study area pastoralists emphasized the need for locally adaptable livestock health service delivery. Although pastoralist strategies to improve livestock health differed by ethnic group, many pastoralists as well as extension officers and government veterinarians identified livestock health education and training for pastoralists and extension officers as a critical need.

Policies designed at the regional, rather than the local, level may not reflect the disease concerns of the entire area. To effectively address veterinary health problems and make livestock herds more resilient to environmental change, conditions at the local level must be considered. Education targeted to pastoralist households and extension officers could achieve greater flexibility in the livestock health system and provide more reliable information about local conditions for governmental policymakers.
\end{abstract}

Keywords: Tanzania; Ruaha; Pastoralists; Education; Livestock health; Zoonotic disease; Extension; Environmental change

\section{Background}

Pastoralists, historically nomadic and semi-nomadic herders dependent upon their livestock as a source of nutrition, cultural status, and a store of wealth (Lybbert et al. 2004), have struggled to maintain their way of life (Waller 1999). Research on limitations to the traditional pastoralist system has focused largely on pasture and water availability, but animal health is also a critical component of

\footnotetext{
* Correspondence: cgustafson6@unl.edu

${ }^{\dagger}$ Equal contributors

'One Health Institute, University of California, Davis, One Shields Ave., Davis, CA 95616, USA

2Department of Agricultural Economics, University of Nebraska-Lincoln, Lincoln, NE 68583, USA

Full list of author information is available at the end of the article
}

sustainable livestock production and livelihoods. Models of livestock systems in northern Tanzania suggest that disease may limit livestock populations more than forage availability (Boone et al. 2002). In addition to increasing livestock morbidity and mortality, disease can reduce pastoralists' income due to lower market prices for sick animals, quarantines, and loss of public trust in animal products (Barrett et al. 2003; Morton 2007).

In semi-arid regions, livestock populations, and therefore pastoralists, are extremely vulnerable to changes in the environment including alterations in climate and resource availability (Dinar et al. 2008). Predicted variability in temperatures and the amount and intensity of rainfall in East Africa have the potential to directly impact livestock

\section{实 Springer}


productivity by altering the quality and availability of water and pasture (Thornton et al. 2009). However, changing weather patterns will also likely impact herd resilience by altering disease dynamics (Ostfeld 2009; Thornton et al. 2009). Although not all pathogens respond similarly to climate change, altered rainfall and temperature patterns can increase disease emergence and transmission. Response of disease vectors, animal hosts, and pathogens to climate change may increase outbreaks of diseases like Rift Valley fever, which can cause severe symptoms and even death in livestock and people (Martin et al. 2008; Gould and Higgs 2009). Extreme rainfall events linked to climate change have the potential to accelerate waterborne pathogen transport and transmission (Patz et al. 2000). Climate variability (e.g. extended periods of drought or sudden floods) can also stress livestock, increasing their susceptibility to disease.

In the biologically diverse and economically important Ruaha landscape of Tanzania, livestock production is a critical, yet threatened, source of income. Pastoralist communities dependent on the natural resource base already face water scarcity and significant livestock disease losses (Coppolillo et al. 2009; Mwakalila 2011). The economy and health of the area is linked to the Great Ruaha River, which serves as a critical source of fresh water for people, livestock, and wildlife; hydropowergenerated electricity for Tanzania's national grid; and irrigation for large- and small-scale farming operations (Newmark 2010; Walsh 2012). In recent decades, significant hydrologic disruption of the Great Ruaha River, caused at least in part by diversion of water for agricultural production, has limited freshwater delivery, driving human, livestock, and wildlife populations into closer contact around restricted resources (Kashaigili 2008; Walsh 2012). Authorities blamed pastoralists living in the headwaters of the Great Ruaha River for the annual disruption of the river, leading to their eviction and, in some cases, movement into the village lands bordering Ruaha National Park (Tenga et al. 2008), increasing human and livestock population pressures in the area. Water scarcity, whether driven by human use or climate change, also has the potential to increase the risk of disease spillover among people, wildlife, and domestic animals sharing limited water sources in the Ruaha landscape (Coppolillo 2004; Mazet et al. 2009).

Human demands on local resources, limited veterinary services, and an expected increase in climatic variability featuring severe weather and intermittent, extensive periods of drought in East Africa (Hulme et al. 2001; Paavola 2008) are likely to increase adverse disease impacts on already burdened livestock populations in the Ruaha landscape. Known diseases in this area with the potential to decrease livestock production and to be exacerbated by climate change include zoonotic tuberculosis
(Mycobacterium bovis), contagious bovine and caprine pleuropneumonia (CBPP and CCPP, respectively), trypanosomiasis, brucellosis, protozoal diseases such as giardiasis and cryptosporidiosis, and Rift Valley fever (Kazwala et al. 2001; Wilson 2003; Clifford et al. 2008; Mazet et al. 2009; Roug et al. 2014). The availability of livestock health services and laboratory diagnostic tools to identify and treat disease in villages near Ruaha National Park is limited, a situation not uncommon in pastoral regions in Tanzania (Rutabanzibwa 2002). In rural villages where livestock keepers rely on these limited services, it is important to understand pastoralists' livestock health concerns and goals since their priorities will impact the success of efforts led by government extension officers and non-community members.

Working with community and government stakeholders, we investigated pastoralist access to livestock health services and local livestock production challenges. Within this framework, we addressed two central research questions related to sustaining herd health and pastoralist livelihoods in a changing environment: 1) How do livestock disease priorities differ among pastoralists, livestock extension officers serving multiple rural villages, and government veterinarians responsible for veterinary services and surveillance across broad geographic areas; and 2) what actions are needed to decrease livestock disease and increase herd resilience to environmental change? Using pastoralist focus groups with representatives from 21 rural villages to complement interviews with pastoralist household leaders, we designed our research to identify livestock diseases of concern, livestock health service needs, and strategies to improve herd health in pastoralist communities. We interviewed government extension officers and government veterinarians responsible for animal health in the Ruaha landscape to assess perceptions of livestock disease challenges and solutions at multi-village to zonal (multi-regional) levels. We report spatial differences in pastoralist-identified diseases of concern as well as differences in disease priorities among pastoralist, extension officer, and government veterinary stakeholders, highlighting the importance of locally adapted animal health services. Stakeholders at all levels identified livestock health education for pastoralist households and livestock extension officers as a key strategy for increasing livestock health and herd resilience.

\section{Study area}

Within the Ruaha landscape, we focused on livestock keepers living in Pawaga and Idodi, two contiguous, rural divisions comprising 21 villages in Iringa Rural District, Iringa Region, Tanzania (Figure 1). Situated in the lowlands of the Rift Valley, Pawaga and Idodi divisions border vast protected areas (Ruaha National Park and community wildlife management areas) to the west 

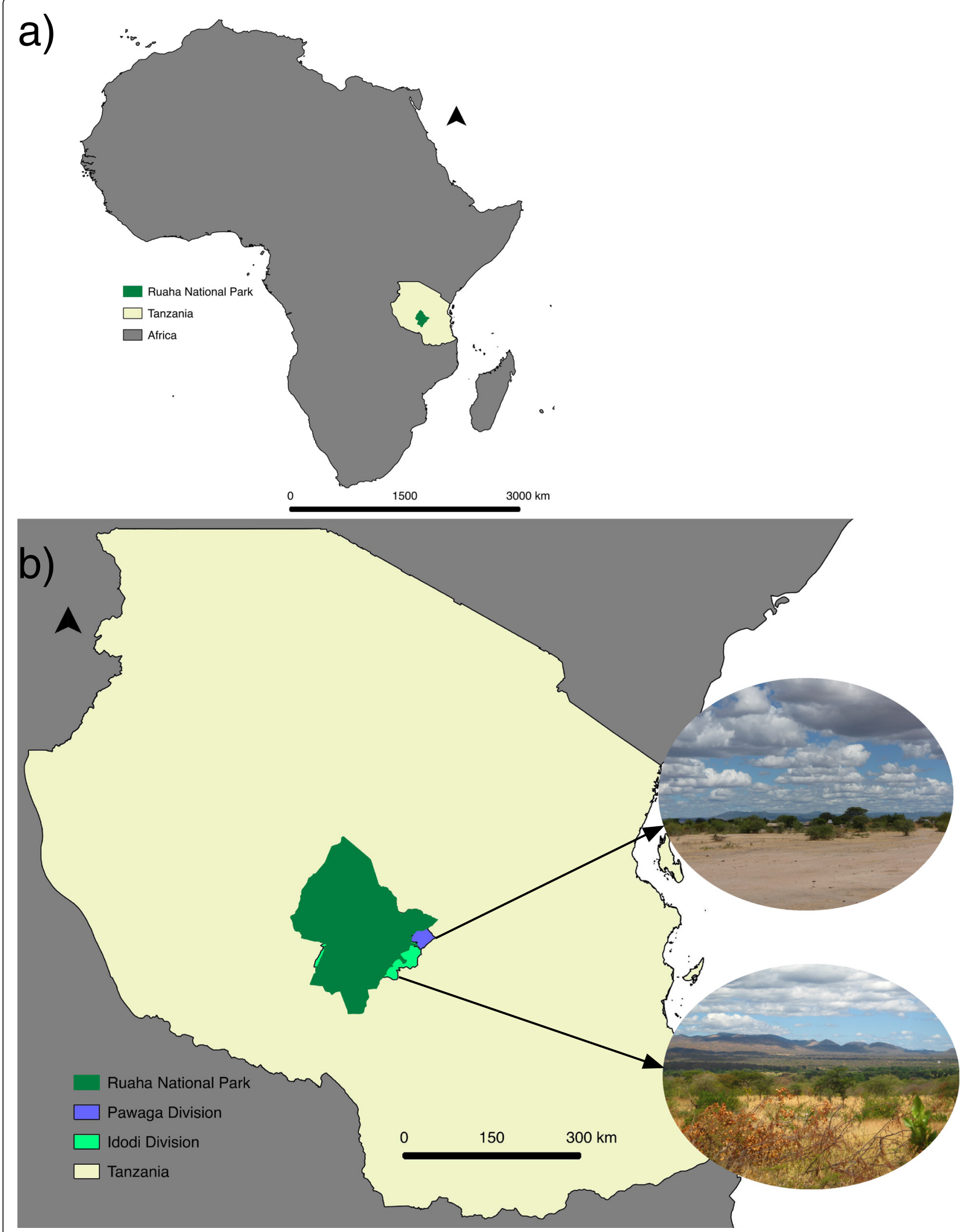

Figure 1 (See legend on next page.) 
(See figure on previous page.)

Figure 1 Map of the study area within (a) Africa and (b) Tanzania. Pastoralist household surveys and focus groups were conducted in rural villages bordering Ruaha National Park in Pawaga and Idodi divisions of Iringa Rural District, Iringa Region, Tanzania. The northern study division (Pawaga) is characterized by semi-arid savannah vegetation while miombo woodlands dominate the less arid southern division (Idodi).

and north, an escarpment to the east, and mountains to the south. The study region is located at a transition point between ecosystems, from the northern AcaciaCommiphora zone dominated by semi-arid savannah vegetation to the southern Brachystegia zone characterized by miombo woodlands (Williams 2005). The climate of Pawaga and Idodi divisions is semi-arid to arid, with bi-modal rainfall patterns providing approximately $500 \mathrm{~mm}$ annually (Walsh 2000; Arnold 2001). The amount of rainfall increases along the northeast-southwest gradient of the divisions, with more precipitation in the southern villages creating a wetter environment than that found in the northern villages. Figure $1 \mathrm{~b}$ illustrates typical differences in the northern and southern environments of the study area.

Pawaga and Idodi village residents are predominantly Hehe and Bena agriculturalists (Dickman 2008), while pastoralist and agro-pastoralist livestock keepers from three predominant ethnic groups - the Barabaig, Maasai ${ }^{\mathrm{a}}$, and Sukuma - typically inhabit marginal lands outlying the village houses and farms. In many areas of East Africa, factors including economic opportunities, access to social services, and land use changes (e.g. agricultural expansion and gazetting of lands for protected areas) have reduced pastoralists' movements (Galvin 2009). The historically nomadic or semi-nomadic pastoralist tribes in our study area (Maasai and Barabaig) have become more sedentary and have diversified their livelihoods. Similar to the Sukuma agro-pastoralists, the majority of the Maasai and Barabaig in the study area have established permanent households, raise crops annually, and send at least one child to school. From this point on, the term 'pastoralists' is used to describe both pastoralist and agro-pastoralist livestock keepers.

The government extension system in the study area consists of six to eight livestock extension officers (LEOs) and 12 agricultural extension officers (AEOs), who are managed by the Iringa District Veterinary Officer and District Agricultural Officer, respectively. LEOs are stationed at the ward level; there are three wards in each of the two districts in the study area. AEOs are assigned to cover one to two villages each.

Livestock extension officers have multiple roles in the study area. For diseases deemed to be of public importance, they participate in vaccination campaigns, which are directed by the district veterinary office. These mass vaccination campaigns are rarely implemented, however.
LEOs also directly provide livestock health services to pastoralist households, including examining sick animals and administering drugs and vaccines, for a fee. LEOs also provide meat inspection services at village abattoirs. There are no functioning veterinary laboratories in the study area to support diagnostic testing. AEOs' main duties are to provide support to farmers in the area, though they also report being asked to address livestock health issues in those villages in which households do not have access to a LEO. AEOs are not legally allowed to purchase or administer most veterinary drugs, with the exception of certain topical products.

Though the Government of Tanzania initiated a programme to gradually privatize veterinary services over a decade ago, implementation began in urban and periurban areas, while it was delayed in rural Tanzania out of concern that private veterinary health providers would not offer their services in rural areas (Rutabanzibwa 2002). There are not currently any private veterinarians or community animal health workers (CAHWs) providing services to pastoralists in the study area.

\section{Methods}

In 2011, we interviewed representatives from 31 pastoralist households - 13 in Pawaga, 18 in Idodi - representing 13 of the 21 villages in the study area. A household comprised all people who lived at one homestead, which included multiple generations of a family led by the head of household. The pastoralist households were selected through a stratified random sampling approach from a sampling frame of pastoralists identified by previous research in the two study area divisions (Coppolillo et al. 2009; Roug et al. 2014). When the head of household was not available (5 of 31 households), another household member involved in livestock management decision-making completed the survey. We also surveyed eight extension officers and three government veterinary officials about livestock diseases of concern and access to livestock health services in the areas they served. Each extension officer provided livestock health services to multiple villages within a study division. One of the three government veterinarians was responsible for oversight of veterinary extension services and disease surveillance in Iringa Rural District, an area that includes Pawaga and Idodi divisions (Figure 2). The remaining two government veterinarians were responsible for disease surveillance and laboratory services for the much larger Southern Highlands Zone (Figure 2). 


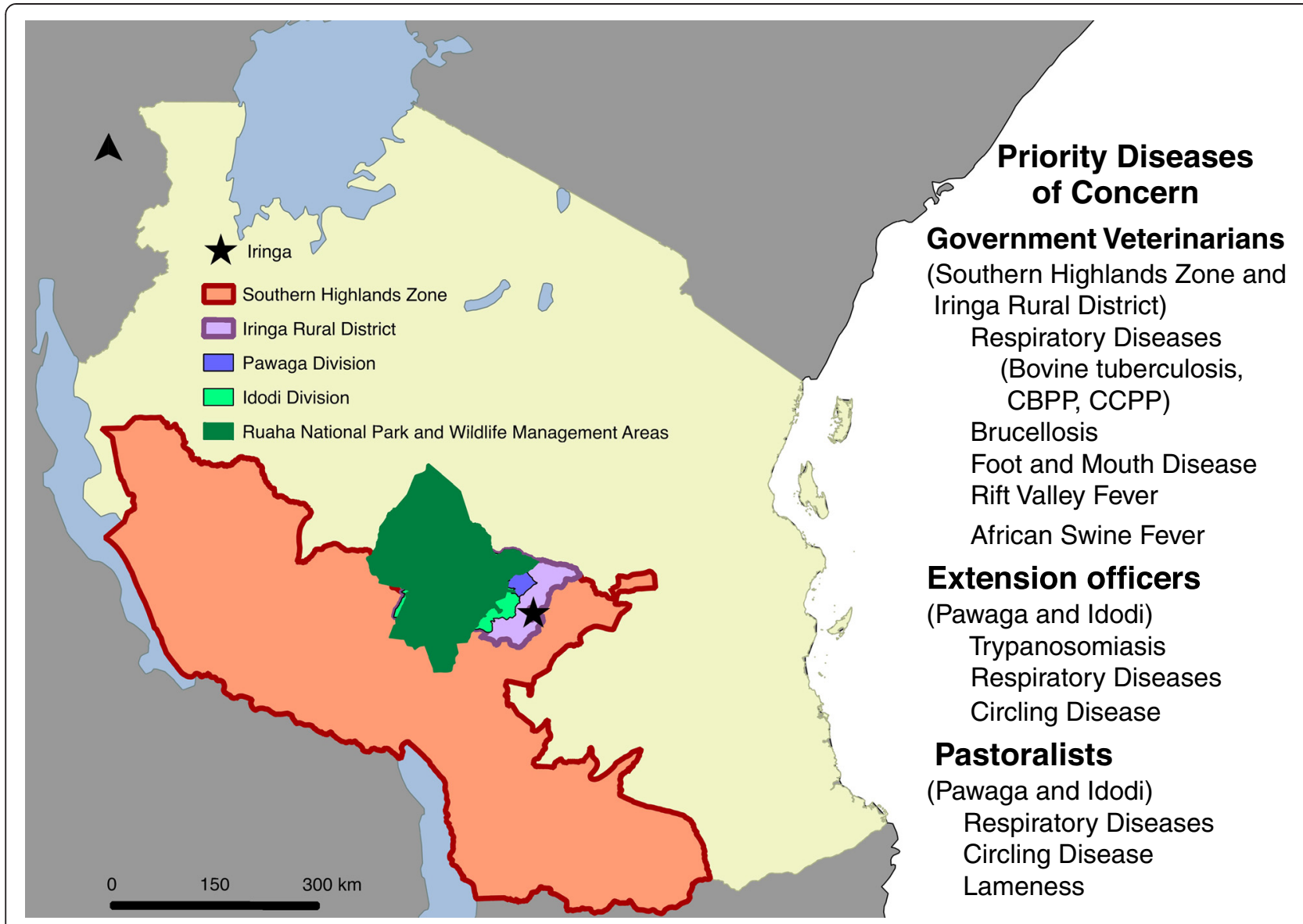

Figure 2 Priority livestock diseases of concern identified by stakeholders at multiple geographic levels in south-central Tanzania.

Priorities differed among stakeholders focused on livestock health at three nested geographic levels: 1) government veterinarians responsible for surveillance in the Southern Highlands Zone or extension services in Iringa Rural District, 2) extension officers delivering livestock health services to multiple villages within Pawaga and Idodi divisions, and 3) pastoralist households within Pawaga and Idodi divisions.

Trained Tanzanian field researchers conducted the interviews with pastoralists and extension officers in Kiswahili. Government veterinarians participated in semistructured interviews conducted in English. Pastoralist household interviews and focus groups included questions about livestock holdings, availability of water and pasture resources, availability of animal health resources (e.g. access to medicines, cattle dips, and extension services), incidence and management of disease in livestock herds, and climate change perceptions. Surveys with extension officers focused on job responsibilities, geographic area of responsibility, livestock diseases of importance, and ways to ameliorate the impact of livestock disease in their area. Priority diseases of concern for livestock health were identified by ranking counts of diseases or syndromes reported by pastoralists and extension officers. Government veterinarians jointly identified diseases of concern at the district or zonal level. We also asked extension officers and government veterinarians to describe actions that they believed would most improve health and long-term viability of pastoralists' livestock herds under changing environmental conditions. Finally, pastoralists ranked pathways to achieve improved herd health according to perceived efficacy.

In 2012, we held seven focus groups with pastoralist representatives and local village pastoralist leaders from each of the 21 study villages in Pawaga and Idodi divisions (Figure 3). The purpose of the focus groups was to strengthen and expand upon the information collected from the household surveys. A total of 118 pastoralists (77 men, 41 women) participated in the focus groups, which were conducted in Kiswahili by a trained local field assistant. Representatives from each village included five pastoralists from different households - the elected village pastoralist leader, two male pastoralists, and two female pastoralists. Focus group participants, in contrast to household survey participants, offered a more representative sample of the gender, tribes, and geographic distribution of pastoralists in the study. 


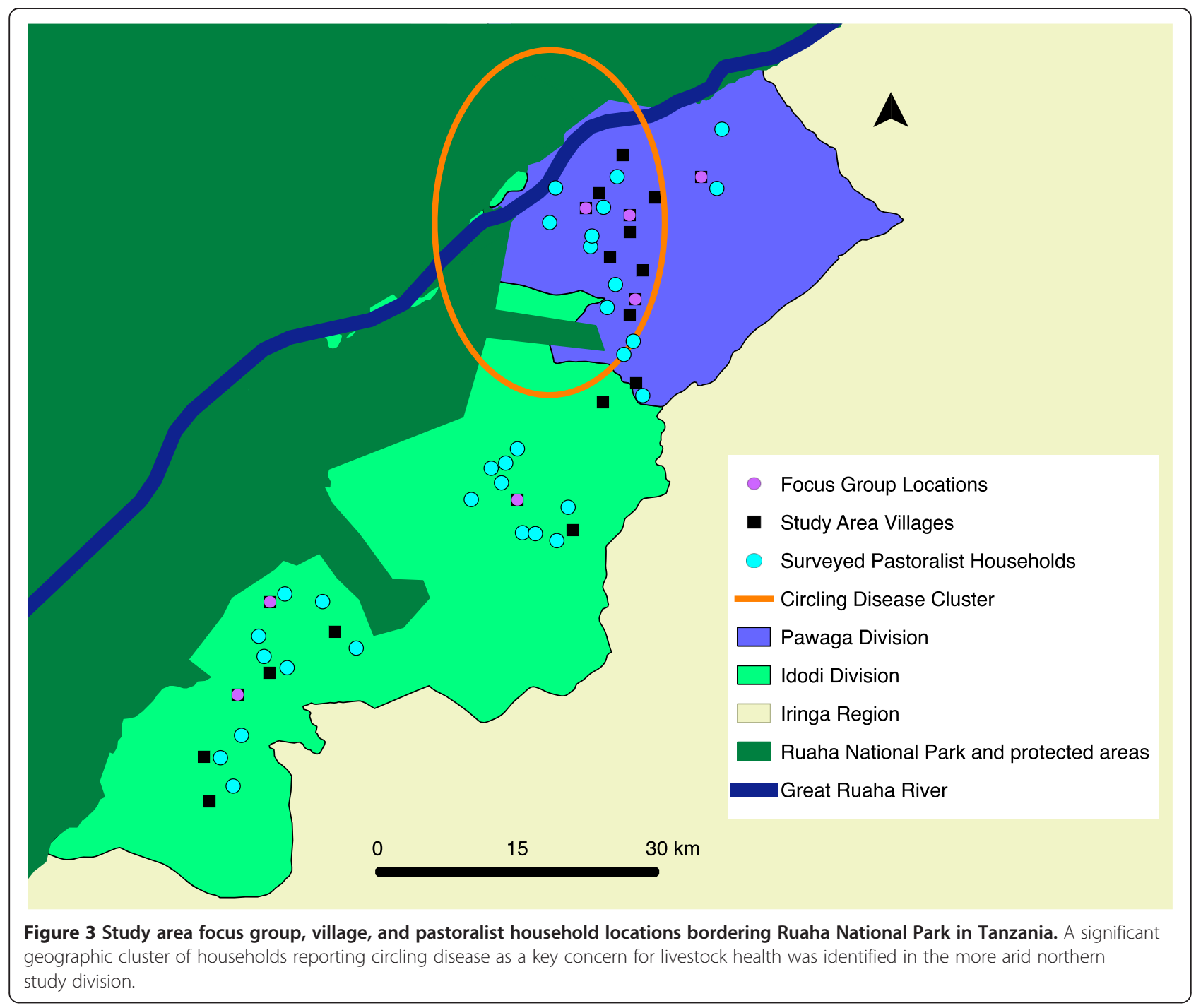

Although there can be challenges in using household interviews and focus groups in research with participants from different tribal backgrounds, we used multiple strategies recommended for qualitative research in Africa to minimize bias and ensure cultural relevance (BrowneNuñez and Jonker 2008). Members of our project team have been exploring local concepts of animal health and building trust with the study communities since 2006 . Additionally, the researcher who conducted surveys and focus groups grew up in the study area villages familiar with pastoralist lifestyles and local context. In both the surveys and focus groups, we used open-ended questions on diseases of concern so that participants could identify a disease by name or describe a disease syndrome based on animal clinical signs. Livestock diseases of concern were discussed in the larger framework of livestock health challenges including resource availability and general environmental change.
For both the household surveys and focus groups, discussions were conducted in Kiswahili. All participants spoke Kiswahili, but we recruited research assistants from the study communities who were fluent in the tribal languages to assist if any confusion with Kiswahili arose. Prior to fieldwork, bilingual Tanzanian researchers on the research team translated interview and focus group questions from English to Kiswahili. Questions were back-translated to English to ensure accuracy. We then pre-tested and refined the survey and focus group questions with local pastoralists in an iterative process until the research team was satisfied that the questions conveyed the intended meaning. Working with the livestock extension officers and pastoralists in the study area, we also identified disease names in English, Kiswahili, and the three tribal languages to insure that pastoralists could describe a disease using familiar terminology. We used multiple data collection methods to strengthen our 
data on stakeholder perceptions of access to livestock health services, challenges to livestock production, livestock diseases of concern, and potential strategies to improve herd health. As the sample size for interviewed households was small, the focus groups were undertaken to cross-validate and expand upon information from the survey responses. While local politics and power dynamics can influence the data collected in focus groups, the reported livestock production constraints, diseases of concern, and strategies to improve herd health agreed with those from the individual interviews, suggesting that the focus group responses were not dominated by few individuals.

We analysed the survey data collected for this research using descriptive statistics and two-tailed $t$-tests in $\mathrm{R}$ statistical software (R Development Core Team 2011). Spatial analyses to identify geographic clusters of diseases of concern were conducted in SatScan v. 9.0 using a Bernoulli model elliptical scanning window (Kulldorff et al. 2006). A significance level of $\alpha=0.05$ was used for all statistical tests. We summarized findings from focus group sessions using qualitative methods for focus group data (Stewart 2007). To allow comparison among herds containing multiple species, we converted the three main livestock species - cattle, goats, and sheep - into Tropical Livestock Units (TLUs), an index weighting each species by productive capacity. We considered one TLU equivalent to one cow, 10 goats, or 10 sheep (Lybbert et al. 2007).

\section{Results}

\section{Access to livestock health services}

One of the most frequently - and passionately - mentioned problems that pastoralists face is a lack of access to livestock health inputs. These inputs fall into three general categories: 1) veterinary extension services, 2) health-related infrastructure, and 3) medicines, and reflect livestock production challenges identified in diverse areas of Africa (Schelling et al. 2005; Chengula et al. 2013). All surveyed households reported treating their sick animals, but $58 \%$ of households (18 of 31) also sought advice from extension officers at times when they were not familiar with the disease or had many sick animals. However, in surveys and focus groups, pastoralists reported that the lack of access to extension officers and commercial medicines presented a significant problem for the health of their animals.

When their livestock were ill, pastoralists did not feel they could rely on the extension officers to provide timely, effective services. All of the parties involved government veterinary officers, livestock extension officers, and pastoralists - agreed on some of the challenges facing the extension system. For instance, extension officers are not commonly provided with transportation as part of their job, hampering their ability to arrive at a pastoralist household in a timely manner, particularly if multiple households request their services. Six pastoralist households reported that they never use extension services because the extension officers would or could not come to their households. While four surveyed extension officers had access to a motorcycle (sometimes shared with other government workers in the area), limited funds for fuel frequently constrained their ability to reach pastoralist households. Two extension officers used bicycles; others travelled by foot within their multivillage area of responsibility.

Local animal health infrastructure constraints included livestock dips (used to control external parasites such as ticks) in need of structural repair and also the limited numbers of dips serving a large pastoralist population. There were only three functioning dips available to pastoralists in the 21 villages with many pastoralists living hours to days away from these services. Additionally, acquiring the medicines necessary to treat sick livestock poses a significant challenge to pastoralists and extension officers. The closest veterinary pharmacies are in Iringa, a three- to four-hour one-way bus ride from the study villages; needing to travel a long distance to access veterinary services is a common problem in Africa (Schelling et al. 2005). Pastoralists primarily travel by foot, bicycle, or bus, creating opportunity costs to obtaining health care beyond the price of the services. Though veterinary medicines are sometimes sold at the livestock markets held in Pawaga and Idodi, pastoralists have raised questions about their source and quality. Lack of authentic and accessible medicines has the potential to delay critical treatment for sick livestock, and experiences with ineffective medicines may reduce pastoralists' future willingness to invest in other treatments.

\section{Pastoralist livestock holdings and disease}

Three self-identified ethnic groups were represented in the sample of 31 pastoralist households - Barabaig (7), Maasai (14), and Sukuma (10). ${ }^{\mathrm{a}}$ The predominant species of livestock raised by interviewed pastoralists were cattle, goats, and sheep. Households held, on average, 90 cattle, 45 goats, and 26 sheep. The average household in this sample owned nearly 100 TLUs, with a minimum herd size of 22 TLUs and a maximum of 519 TLUs. Though inter-tribal differences in livestock holdings were not statistically significant due to our small sample, in general the Maasai kept fewer cattle, resulting in fewer TLUs owned by the Maasai compared to the Barabaig or Sukuma.

Pastoralists reported different levels of disease in their herds over the 12 months prior to the survey. At the household level, the percentage of the herd affected by disease ranged from less than $1 \%$ to over $30 \%$ of animals. The most prevalent health problems reported 
were respiratory and neurologic conditions, both of which affected livestock in almost $40 \%$ of households. While CBPP and CCPP are common in the study area, cases of respiratory disease may also be due to other causes such as bovine tuberculosis. The neurologic condition, kizunguzungu or 'circling disease', was described as a circling behaviour followed by rapid deterioration and death in goats or sheep. In preliminary investigations of the affected livestock, clinical signs and brain lesions were consistent with symptoms caused by cysts of the developing larval stage of a tapeworm (Taenia multiceps) shed by domestic dogs and wild canids. Circling disease is a growing concern among pastoralists in the study area due to high mortality in sick animals. Pastoralists in all focus groups also included respiratory disease and circling disease among the most threatening diseases to their livelihoods.

Even within the limited study area, spatial differences existed in pastoralists' diseases of concern. In household surveys and focus groups, circling disease was more commonly described as a priority concern in Pawaga, the northern division of the study area, than in Idodi $(P<0.001)$. In Pawaga, $77 \%$ of households identified circling disease as a threat to their herds and livelihoods, while only $12 \%$ of households in Idodi were concerned about the impact of circling disease. Even with the small sample of households, spatial analyses identified a significant geographic cluster of households reporting circling disease as a critical concern for livestock health in Pawaga $(P<0.001$, Figure 3$)$. The spatial differences in the circling disease concerns were also reflected in extension officer responses. Two of the three extension officers who named circling disease as a disease of concern were based in Pawaga.

\section{Diseases of concern at pastoralist household, village extension officer, and district or zonal veterinary official levels}

Pastoralists, extension officers, and government veterinarians agreed that respiratory diseases are a key concern, but expressed different views on additional important diseases threatening livestock health in their overlapping geographic areas of responsibility (Figure 2). District and regional veterinarians recognized circling disease as a specific, local concern for Pawaga and Idodi livestock, but not a concern on the larger zonal scale, where decisions on resource allocation are frequently made.

\section{Household, village, and district/zonal perspectives on actions to improve livestock health}

Pastoralists, extension officers, and government veterinarians ranked actions to improve the health of livestock from the most to the least useful. While veterinarians and extension officers self-identified these actions, pastoralists selected from a list of five options developed with community members in the survey testing phase: 'more cattle dips', 'livestock health research', 'additional education and training for extension officers', 'livestock health education for pastoralists', and 'increased availability of medicines in the villages'. Pastoralist respondents could also provide their own options, though only one did, listing 'provide water for livestock in the dry season'.

The pastoralist rankings of actions to improve livestock health differed by ethnic group. Maasai and Sukuma preferences were similar, with both ethnic groups ranking increased availability of medicines in the villages first, pastoralist education second, and extension officer education third. The Barabaig placed less emphasis on education $(P=0.02)$, ranking cattle dips, medicines in the villages, and research above extension officer and pastoralist education. However, during pastoralist focus groups, participants from all three tribes emphasized the importance of education on livestock health topics including identifying clinical signs of disease and understanding appropriate disease treatment and prevention. While knowledge of emerging diseases (such as circling disease) was considered important for all pastoralists, one participant emphasized the need for ongoing education about common existing diseases, such as parasitic infections, to help transfer knowledge to younger members of the households. Pastoralists from all tribes echoed the desire for education to be extended to all members of the household. Both female and male pastoralists stressed that it was necessary that women have access to livestock health education. In all groups, disease was discussed as a critical factor limiting livestock production, and livestock health education was confirmed as a priority for increasing herd health and resilience.

Extension officers identified continuing education for themselves and pastoralists and access to diagnostic tests as the most important actions to improve herd health, closely followed by better transportation to reach pastoralist households. Only one extension officer listed more cattle dips, which were also ranked as a low priority by the government veterinarians. The veterinarians ranked education for pastoralists and extension officers as equally important priorities, followed by better transportation and diagnostic tests.

\section{Additional challenges to livestock production and livelihood improvement}

While focus group participants consistently mentioned disease as limiting herd and household well-being confirming household survey results - other impediments were also identified, including human capital development, insufficient opportunities to market animals or livestock products, and changes in environmental resources. 


\section{Economics, markets, and knowledge}

Pastoralists see few opportunities to sell livestock and livestock products at a 'fair' price in Pawaga and Idodi divisions. While small-scale sales of livestock products such as milk and eggs occur locally, each division has only two markets that offer the chance to sell livestock. One of these markets opens two days per month; the other three are held one day per month. Pastoralists from all seven focus groups listed a more robust local livestock market as an important need. Focus group representatives in both divisions also described training on economics, entrepreneurship, and livestock marketing education as vital to improved livelihoods. Additionally, many pastoralist women requested training in literacy and numeracy.

\section{Pasture and water shortages - shared landscapes and environmental change}

Representatives at all of the focus group sessions mentioned pasture and water shortages as limitations to livestock production. Pastoralists perceived lack of pasture to be driven by increased demand for land by agriculturalists; many pastoralists said that the amount of land available to them has decreased considerably in the recent past. Pastoralists voiced concerns about water quality and quantity, linking problems with water to human population expansion and changing land use patterns. For example, in addition to increasing competition for available water, new agricultural development has physically blocked livestock access to surface water sources. Destruction of forests for charcoal production and farming as well as increased harvest of remaining trees near water sources for cooking fuel were identified as important drivers of decreased water quality. Pathogen contamination of water sources was not discussed, but pastoralists in one focus group emphasized the potential for agricultural chemical run-off to decrease water quality.

Pastoralists in all focus groups agreed that changing precipitation patterns also contribute to limited pasture and water resources. They suggested that the climate throughout the study area is becoming warmer and drier, with rainfall decreasing in recent years. While participants largely did not link the cause of decreased rainfall explicitly to human influences, one representative identified it as the result of human use of cars, firewood, and airplanes. As the human population grows in this area, pastoralists perceive increased resource consumption demands, land use decisions, and climate change as critical to both water and pasture availability.

\section{Discussion and conclusions}

Pastoralists living in the rural study villages near Ruaha National Park face challenges common to pastoralists in other regions of sub-Saharan Africa, including lack of livestock health services, pasture and water scarcity, and limited access to livestock markets (e.g. Lybbert et al. 2004; Mosalagae and Magotsi 2013). Livestock disease was identified as a limiting factor to pastoralist livestock production and herd sustainability at multiple stakeholder levels, but some disease priorities differ among pastoralists, government extension officers, and veterinary officials responsible for disease surveillance and services at broader geographic levels. The combination of disease and decreased access to pasture and water resources represents a significant threat to the pastoralist system in the Ruaha landscape. In the face of climate variability and landscape change, targeted livestock health education for pastoralists and extension officers was identified as a common pathway for improving herd health and resilience. Given differences in disease priorities among stakeholder groups and spatial differences in livestock disease concerns within the study area, education strategies must remain adaptable to local needs and include female and male participants from the diverse pastoralist and agro-pastoralist tribal groups.

As anticipated by Rutabanzibwa (2002), privatization has not led to the provision of livestock health services in many rural areas of Tanzania. In the study villages, private veterinarians have yet to establish practices, leaving extension officers as the primary providers of veterinary health care. Pastoralists, extension officers, and government veterinarians agreed on key challenges limiting access to livestock health services in the rural Ruaha landscape. Resource limitations, including lack of transportation and diagnostic supplies, restricted the ability of extension officers to visit pastoralist households and diagnose sick animals, which can lead to a breakdown in trust of the veterinary service system (Mugambi et al. 2012). The distance from households to extension officers and livestock pharmacies also impacted pastoralist access to health services and treatment for their animals. In the case of an outbreak of climate-driven disease, like Rift Valley fever, these distances and diagnostic obstacles could prevent the efficient disease surveillance, reporting, and treatment necessary to protect animal and human health. Limited access to extension officers and livestock treatment options may also increase the potential for the spread of zoonotic pathogens from infected cattle, sheep, and goats to their pastoralist keepers.

While some key diseases (respiratory diseases) were reported as important by all groups of stakeholders, differences in other priority diseases for regional or district, village, and household levels emphasize the need for increased communication between policymakers and pastoralists. These differences may also complicate the task of government veterinarians attempting to direct health-care services to combat different disease threats with limited resources. The government veterinarians recognized locally 
important diseases that were not zonal priorities and highlighted pastoralist and extension officer education as a method to address local health risks that are not covered by larger scale veterinary services. Small-scale spatial differences in diseases threatening pastoralist livestock herds underscore the importance of adapting livestock health services to local needs. Additionally, tribal differences in ranking preferred approaches to make livestock more resilient to climate change-driven disease suggest that there are no available 'blanket' policies that all pastoralists believe would improve livestock health. In order to maximize pastoralists' trust in and access to veterinary and extension services, local priorities must drive investment in the livestock health system, requiring a flexible, stakeholder-led approach.

Despite the increased challenges to pastoralist communities, there are a number of factors that may promote improvement of their livelihoods. For one, global demand for livestock products has been increasing rapidly, particularly in developing countries, leading some to label the trend a 'livestock revolution' (Delgado et al. 2001; Rosegrant et al. 2001). Though the local effects of changes in global demand may not be seen as acutely in rural communities, the global trends are mirrored by increases in demand for meat and other animal products from local and regional consumers (Diao et al. 2005).

Increasing the capacity of veterinarians, extension officers, and pastoralists themselves to meet the requirements of local trade channels - promoting food safety and preventing seriously damaging outbreaks of livestock disease - can increase pastoralists' wealth, nutritional status, and access to education (Scoones and Wolmer 2006). Evidence exists that this type of strategy can markedly improve the productivity of pastoral livestock systems. Training animal health specialists to provide livestock health services has proved quite effective in disease recognition and surveillance; workers trained on disease reporting methods in three districts of the Arusha region in Tanzania increased the number of reported disease cases by $49 \%$ - to the highest levels in the country (Allport et al. 2005). However, uninformed or undertrained veterinary extension officers - or poor communication with pastoralists - can be counterproductive, reducing pastoralist trust in effective treatment methods (Mugambi et al. 2012).

To supplement the formal veterinary extension system, governments and aid groups have experimented with training community-selected representatives to provide livestock health services (Catley et al. 2004). A project that trained community animal health workers (CAHWs) in northern Tanzania experienced reductions in calf mortality between 59\% and 93\% (Nalitolela et al. 2001). Though CAHW models of health services have been effective in strengthening veterinary services and herd health, programmes to train CAHWs are primarily donorled efforts (Allport et al. 2005), and many CAHW systems have not been sustainable without ongoing donor support (Catley et al. 2004).

Providing livestock health education directly to pastoralist households offers an alternative route to improved animal health and pastoralist livelihoods as well as an opportunity to expand educational opportunities for women and multiple tribal groups. In addition to increasing recognition of and response to local diseases of concern, pastoralist livestock health education has the potential to increase awareness of zoonotic diseases and prevention practices to limit transmission from livestock to people. Though untested, there are a number of features suggesting that household-level livestock health education could prove successful. Inclusive, community-focused training with male and female pastoralists in Ethiopia, including livestock management and marketing, substantially improved pastoralists' livelihoods (Coppock et al. 2011). Pastoralists have intimate knowledge of their animals and are acutely aware of signs of livestock diseases. In a study assessing veterinarians' and pastoralists' livestock health knowledge, pastoralists compared favourably with veterinarians, which suggests that disease surveillance in remote, rural areas could be strengthened by integrating pastoralists' livestock health knowledge and observation of disease into veterinary health systems (Catley 2006). Pastoralists in our study also identified the inclusion of women in household education as a critical need. While in many ways household members work towards common goals, women and men maintain separate spheres of responsibility; control of resources generated in female-led activities differs from that generated in male-led activities (Anderson and Eswaran 2009). Women, more than men, tend to use resources in ways that benefit the household as a whole (Senauer 1988) and have more say in household decision-making when they contribute more income to the household (Manser and Brown 1980). Providing education to community members - including many women - improved households' well-being during a severe drought (Coppock et al. 2011).

Pastoralists have many traditional disease remedies, but the emergence of novel or unknown diseases and the reduction of the natural resource base from which these traditional remedies derive compromise their ability to rely on traditional knowledge. From pastoralist and local government perspectives, an increase in the health-care services available to pastoralists and additional investment in pastoralist knowledge are needed to cope with livestock health challenges. In Tanzania and beyond, locally relevant livestock health education has the potential to make pastoralists' livestock herds and livelihoods more resilient in a landscape rapidly being altered by environmental change. 


\section{Recommendations}

A complex, interdependent strategy to increase trust between the local livestock extension officers and pastoralist community, leading to improved communication and a greater understanding of local livestock health needs, should be considered. This strategy requires that veterinary authorities emphasize the importance of communication between extension officers and pastoralists and provide infrastructure or incentives to extension officers to make visits to pastoralist households if and when requested. Increased communication will simultaneously provide a conduit for local knowledge to the district or regional level, allowing veterinary authorities to craft strategies or policies that reflect on-the-ground needs and control locally important and livelihood-impacting diseases. Providing additional livestock health training for rural extension officers has the potential to improve both the quality of livestock health services delivered, as well as pastoralist trust in extension officer knowledge and capacity. Education programmes jointly targeting pastoralist households and extension officers may offer a synergistic route for improving herd health in a rapidly changing environment.

\section{Endnote}

${ }^{a}$ Williams (2005) identifies the Maasai pastoralists living in the Idodi rangelands in the southern division of the study area as Ilparakuyo, which is a branch of the Maasai. However, all respondents identified themselves simply as Maasai.

\section{Abbreviations \\ AEO: agricultural extension officer; CAHW: community animal health worker; CBPP: contagious bovine pleuropneumonia; CCPP: contagious caprine pleuropneumonia; LEO: livestock extension officer; TLU: tropical livestock unit.}

\section{Competing interests}

The authors declare that they have no competing interests.

\section{Authors' contributions}

CG, EV, RK, WS, and JM designed the research. AM, GP, EV, and CG performed the research. CG and EV analysed the data and wrote the manuscript. RK, WS, AM, GP, and JM critically reviewed the manuscript. All authors read and approved the final manuscript.

\section{Authors' information}

All authors collaboratively conducted this research as part of the Health for Animals and Livelihood Improvement (HALI) Project based in Iringa, Tanzania. HALI is a long-term One Health research partnership between Sokoine University of Agriculture and the University of California, Davis. CG is an agricultural economist; GP is a veterinarian; EV, RK, WS, and JM are veterinary epidemiologists; $\mathrm{AM}$ is a community development specialist. CG and EV are co-first authors.

\section{Acknowledgements}

This research was funded by grants from the USAID Feed the Future Livestock and Climate Change Innovation Lab at Colorado State University. The funders had no role in the collection, analysis, and interpretation of data; writing of the manuscript; or decision to submit the manuscript for publication. We thank the Tanzania Commission on Science and Technology (COSTECH) for granting field research approval (Research Permit No. 2012-272-NA-2012-45) and Dr. Mathias Matandala for his assistance in identifying and contacting the extension officers.
We also thank lan Gardner for the valuable insight and comments and the pastoralists, livestock extension officers, and veterinary officials who participated in the field surveys and focus groups. Interviews and focus group research were also approved by the University of California, Davis Institutional Review Board (Protocol No. 240188-1).

\section{Author details}

1One Health Institute, University of California, Davis, One Shields Ave., Davis, CA 95616, USA. ${ }^{2}$ Department of Agricultural Economics, University of Nebraska-Lincoln, Lincoln, NE 68583, USA. Department of Veterinary Medicine and Public Health, Sokoine University of Agriculture, PO Box 3021, Chuo Kikuu, Morogoro, Tanzania.

Received: 1 October 2014 Accepted: 23 December 2014

Published online: 31 January 2015

\section{References}

Allport, M, S Bahari, and A Catley. 2005. The use of community-based animal health workers to strengthen disease surveillance systems in Tanzania. Revue Scientifique et Technique- Office international des épizooties 24: 921-932.

Anderson, S, and M Eswaran. 2009. What determines female autonomy? Evidence from Bangladesh. Journal of Development Economics 90: 179-191.

Arnold, C. 2001. MBOMIPA/Tanzania case study: wildlife, poverty, and livelihood linkages. In Wildlife and poverty study: phase one report, 31, ed. J Elliott, 73-92. London: Livestock and Wildlife Advisory Group, Department for International Development.

Barrett, CB, F Chabari, DV Bailey, PD Little, and DL Coppock. 2003. Livestock pricing in the northern Kenyan rangelands. Journal of African Economies 12: 127-155.

Boone, RB, MB Coughenour, KA Galvin, and JE Ellis. 2002. Addressing management questions for Ngorongoro Conservation Area, Tanzania, using the SAVANNA modelling system. African Journal of Ecology 40: 138-150.

Browne-Nuñez, C, and SA Jonker. 2008. Attitudes toward wildlife and conservation across Africa: a review of survey research. Human Dimensions of Wildlife 13: 47-70.

Catley, A. 2006. Use of participatory epidemiology to compare the clinical veterinary knowledge of pastoralists and veterinarians in East Africa. Tropical Animal Health and Production 38: 171-184.

Catley, A, T Leyland, JC Mariner, DMO Akabwai, B Admassu, W Asfaw, G Bekele, and HS Hassan. 2004. Para-veterinary professionals and the development of quality, self-sustaining community-based services. Revue Scientifique et Technique- Office international des épizooties 23: 225-252.

Chengula, A, RH Mdegela, and CJ Kasanga. 2013. Awareness, knowledge and practice of pastoralists and agro-pastoralists towards livestock diseases affecting domestic animals in Arusha, Manyarya and Morogoro regions, Tanzania. Journal of Health, Medicine and Nursing 1: 13-19.

Clifford, D, R Kazwala, and P Coppolillo. 2008. Evaluating and managing zoonotic disease risk in rural Tanzania. GL-CRSP Research Brief 08-01-HALI.

Coppock, DL, S Desta, S Tezera, and G Gebru. 2011. Capacity building helps pastoral women transform impoverished communities in Ethiopia. Science 334: 1394-1397.

Coppolillo, P. 2004. A preliminary situation analysis for the Rungwa-Ruaha landscape, Tanzania, A report to the WWF International Improving Conservation and Development within Ecoregions Programme (Wildlife Conservation Society, Iringa, Tanzania).

Coppolillo, P, D Clifford, A Dickman, M Masozera, M Nguvava, R Kazwala, J Erickson, and J Mazet. 2009. Landscape factors associated with livestock disease deaths in Idodi and Pawaga Divisions, Tanzania, GL-CRSP Research Brief 09-01-HALI.

Delgado, C, M Rosegrant, H Steinfeld, S Ehui, and C Courbois. 2001. Livestock to 2020: The next food revolution. Outlook on Agriculture 30: 27-29.

Diao, X, M Johnson, S Gavian, and P Hazell. 2005. Africa without borders: building blocks for regional growth. IFPRI Issue Brief 38. Washington, DC: International Food Policy Research Institute (IFPRI). http://www.ifpri.org/sites/default/files/ publications/ib38.pdf. Accessed 11 Aug 2011.

Dickman, AJ. 2008. Key determinants of conflict between people and wildlife, particularly large carnivores, around Ruaha National Park, Tanzania. PhD Dissertation, University College London, London, UK.

Dinar, A, R Hassan, R Mendelsohn, and J Benhin. 2008. Climate change and agriculture in Africa: impact assessment and adaptation strategies. London, UK: EarthScan. 
Galvin, KA. 2009. Transitions: pastoralists living with change. Annual Review of Anthropology 38: 185-198.

Gould, EA, and S Higgs. 2009. Impact of climate change and other factors on emerging arbovirus diseases. Transactions of the Royal Society of Tropical Medicine and Hygiene 103: 109-121.

Hulme, M, R Doherty, T Ngara, M New, and D Lister. 2001. African climate change: 1900-2001. Climate Research 17: 145-168.

Kashaigili, JJ. 2008. Impacts of land-use and land-cover changes on flow regimes of the Usangu wetland and the Great Ruaha River, Tanzania. Physics and Chemistry of the Earth 33: 640-647.

Kazwala, RR, DM Kambarage, CJ Daborn, J Nyange, SFH Jiwa, and JM Sharp. 2001. Risk factors associated with the occurrence of bovine tuberculosis in cattle in the Southern Highlands of Tanzania. Veterinary Research Communications 25: 609-614

Kulldorff, M, L Huang, L Pickle, and L Duczmal. 2006. An elliptic spatial scan statistic. Statistics in Medicine 25: 3929-3943.

Lybbert, TJ, CB Barrett, S Desta, and DL Coppock. 2004. Stochastic wealth dynamics and risk management among a poor population. The Economic Journal 114: 750-777.

Lybbert, TJ, CB Barrett, JG McPeak, and WK Luseno. 2007. Bayesian herders: updating of rainfall beliefs in response to external forecasts. World Development 35: 480-497.

Manser, M, and M Brown. 1980. Marriage and household decision-making: a bargaining analysis. International Economic Review 21: 31-44.

Martin, V, V Chevalier, P Ceccato, A Anyamba, L De Simone, J Lubroth, S de La Rocque, and J Domenech. 2008. The impact of climate change on the epidemiology and control of Rift Valley fever. Revue Scientifique et Technique- Office international des épizooties 27: 413-426.

Mazet, J, D Clifford, P Coppolillo, A Deolalikar, J Erickson, and R Kazwala. 2009. A "One Health" approach to address emerging zoonoses: The HALI Project in Tanzania. PLoS Medicine 6: e1000190

Morton, JF. 2007. The impact of climate change on smallholder and subsistence agriculture. Proceedings of the National Academy of Sciences 104: 19680-19685.

Mosalagae, D, and K Mogotsi. 2013. Caught in a sandstorm: an assessment of pressures on communal pastoral livelihoods in the Kalahari desert of Botswana. Pastoralism 3: 18.

Mugambi, JM, FD Wesonga, and SG Ndungu. 2012. Ticks and tick-borne disease control in a pastoral and an agro-pastoral farming systems in Kenya. Livestock Research for Rural Development 24: 1-8.

Mwakalila, S. 2011. Assessing the hydrological conditions of the Usangu Wetlands in Tanzania. Journal of Water Resource and Protection 3: 876-882.

Nalitolela, S, R Allport, H Ndanu, and L Shongon. 2001. Impact of animal health improvement on food security of a pastoralist community in Simanjiro District, Tanzania Veterinary Association Annual Scientific. Proc. 19th Conference. Arusha, Tanzania: Tanzania Veterinary Association; Dec 2001.

Newmark, WD. 2010. Conserving biodiversity in east African forests: a study of the eastern Arc mountains. Ecological studies, vol. 155. Berlin, Germany: Springer-Verlag.

Ostfeld, RS. 2009. Climate change and the distribution and intensity of infectious diseases. Ecology 90: 903-905.

Paavola, J. 2008. Livelihoods, vulnerability and adaptation to climate change in Morogoro, Tanzania. Environmental Science and Policy 11: 642-654.

Patz, JA, TK Graczyk, N Geller, and AY Vittor. 2000. Effects of environmental change on emerging parasitic diseases. International Journal of Parasitology 30: $1395-1405$.

R Development Core Team. 2011. R: A language and environment for statistical computing. R Foundation for Statistical Computing, Vienna, Austria. ISBN 3-900051-07-0. http://www.R-project.org/. Access date: November 5, 2011.

Rosegrant, MW, MS Paisner, S Meijer, and I Witcover. 2001. 2020 global food outlook: trends, alternatives, and choices. Washington, DC: International Food Policy Research Institute (IFPRI).

Roug, A, A Perez, JAK Mazet, DL Clifford, E VanWormer, G Paul, RR Kazwala, and WA Smith. 2014. Comparison of intervention methods for reducing human exposure to Mycobacterium bovis, through milk in pastoralist households in Tanzania. Preventive Veterinary Medicine 115: 157-165.

Rutabanzibwa, AP. 2002. Veterinary legal reform in Tanzania, Proceedings of primary animal health care in the 21st century: Shaping the rules, policies and institutions, Mombasa, Kenya, October 15-18, 2002.
Schelling, E, K Wyss, M Bechir, D Doumagoum Moto, and J Zinsstag. 2005. Synergy between public health and veterinary services to deliver human and animal health interventions in rural low income settings. BMJ 331(7527): 1264-1267.

Scoones, I, and W Wolmer. 2006. Livestock, disease, trade and markets: policy choices for the livestock sector in Africa. Institute of Development Studies Working Paper 269: 1-55.

Senauer, B. 1988. Determinants of the intrahousehold allocation of food in the rural Philippines. American Journal of Agricultural Economics 70: 170-180.

Stewart, DW. 2007. Focus groups: theory and practice. Thousand Oaks, CA: Sage Publications, Ltd.

Tenga, R, A Mattee, N Mdoe, R Mnenwa, S Mvungi, and MT Walsh. 2008. A study on the options for pastoralists to secure their livelihoods in Tanzania: current policy, legal, and economic issues, Volume one: Main report. Arusha, Tanzania: Tanzania Natural Resource Forum. http://www.tnrf.org/files/E-INFORLTF_VOL1_MAIN-REPORT_A_Study_on_options_for_pastoralism_to_secure_ their_livelihoods_in_Tanzania_2008.pdf. Accessed 23 Mar 2014.

Thornton, PK, J van de Steeg, A Notenbaert, and M Herrero. 2009. The impacts of climate change on livestock and livestock systems in developing countries: a review of what we know and what we need to know. Agricultural Systems 101: 113-127.

Waller, RD. 1999. Pastoral poverty in historical perspective. In The poor are not us, ed. D Anderson and V Broch-Due, 20-49. Suffolk, UK: James Currey Ltd.

Walsh, MT. 2000. The development of community wildlife management in Tanzania: Lessons from the Ruaha ecosystem, Paper presented at African Wildlife Management in the New Millennium conference, 13-15 December 2000, Mweka, Tanzania.

Walsh, MT. 2012. The not-so-great Ruaha and hidden histories of an environmental panic in Tanzania. Journal of Eastern African Studies 6: 303-335.

Williams, A. 2005. People cascades, land, and livelihoods: Farmer and herder land-use relations in the Idodi rangelands, Tanzania. PhD Dissertation, University College London, London, UK

Wilson, RT. 2003. Animal health and disease control in the Usangu Wetland of southwestern Tanzania. Tropical Animal Health \& Production 35: 47-67.

\section{Submit your manuscript to a SpringerOpen ${ }^{\circ}$ journal and benefit from:}

- Convenient online submission

$\checkmark$ Rigorous peer review

- Immediate publication on acceptance

- Open access: articles freely available online

- High visibility within the field

- Retaining the copyright to your article

Submit your next manuscript at $\gg$ springeropen.com 